\title{
QUASI-AUTOMATIC MONITORING SYSTEM FOR TURNING OPERATION USING ACOUSTIC EMISSION SIGNAL RESPONSE AND FACTORIAL DESIGN METHOD
}

\author{
F. Davies', L. E. Ansong ${ }^{1}$, P.Y. Andoh ${ }^{2}$, S. P. Owusu-Ofori' ${ }^{2}$, \\ ${ }^{1}$ Department of Mechanical Engineering, Faculty of Mechanical and Agricultural Engineering, \\ Kwame Nkrumah University of Science \& Technology, Kumasi. \\ ${ }^{2}$ Department of Mechanical and Chemical Engineering, \\ College of Engineering, North Carolina Agricultural and Technical State University, \\ Greensboro, NC 27411.
}

\begin{abstract}
This work discusses the generation of a quasi monitoring system intended for an operator to change cutting tool during turning operation. The monitoring system uses the effects of turning variables on acoustic emission signal responses and factorial experimental design approach. In cutting operations, acoustic emission provides useful information concerning the tool wear condition because of the fundamental differences between its source mechanisms in the rubbing friction on the wear land of the single point tool. In this study, effects of cutting speed, feed and tool condition on the acoustic emission signal are investigated using acoustic emission's energy, amplitude, and frequency response and $2^{3}$ factorial design for turning operation. Cutting tests were performed using high-speed steel under dry conditions. Calculated effects, standard errors at $95 \%$ confidence level, and models governing the acoustic emission response to the cutting conditions have been generated from the acoustic emission signal responses. The generated models revealed that acoustic energy response is affected by significant interactions between cutting speed and feed, and insignificant interactions between cutting speed and tool condition, while the acoustic amplitude response is affected by insignificant interactions among cutting speed, feed, and tool condition. These results suggest that acoustic emission's energy and amplitude responses could be used to control the cutting speed and feed during turning operation, thus prolonging the life of the cutting tool.
\end{abstract}

Keywords: Acoustic Emission, Factorial Design, Machining Processes, Tool Life, Cutting Speed

\section{INTRODUCTION}

Experienced machinists monitor the status of machining operations using audible noise from the machining operation. This method of process monitoring is in extensive application, especially for job lot or batch production shops. In some machine shops, machinists attempt to detect a change in the cutting conditions or the tool state from the audible sound of the process, however, there are issues arising out of this method that are of great concern. The noise that emanates from a machining operating system is from the machine 
tool input power source, surroundings, and plastic deformation of the material being processed. Out of these, the noise resulting from plastic deformation is the noise that has correlation with the cutting operation, cutting parameters, and the state of cutting tool. Thus it is this noise that requires monitoring with a view to establishing analytical relationships that may enhance prediction of the state of cutting system. This noise has frequency range of the order of hundredths of kilohertz for metallic materials (Davis, 1989). The human hearing frequency range is generally $16 \mathrm{~Hz}$ to $20,000 \mathrm{~Hz}$, and even then; the hearing system (the ear, and related perception system in the brain) is more sensitive to frequencies in the range of $1000 \mathrm{~Hz}$ to $4000 \mathrm{~Hz}$ (Salameh, 2001). Cho and Komvopoulos, (1997), monitored the machining process and tool condition during turning of AISI 4340 steel with uncoated, two layer coated, and three layer coated cemented carbide tools using acoustic emission (AE) signals. The paper entitled, "Correlation between AE signals and Wear of Multilayer Ceramic Coated Tools", used an approach that considered four different feed rates at constant cutting speed and depth of cut, and each of the cutting tools. According to the paper, $\mathrm{AE}$ frequencies in the range of $100-150 \mathrm{kHz}$ are primarily due to plastic deformation in the near surface tool regions and the primary, secondary and tertiary shear zones of the work piece, whereas cracking leading to coating delamination and grain pull-out generates frequencies in the range of $170-200 \mathrm{kHz}$ (Cho and Komvopoulos, 1997). Clearly, these frequencies are far above human hearing frequency range. It is therefore obvious that the plastic deformation noise cannot be heard, thus the machinists perceived noise is not entirely reliable if it were to be used to determine the critical cutting conditions.

Acoustic emission sensing is one of the techniques for studying the behaviour of materials deforming under stress. AE may be defined as a transient elastic wave generated by the rapid release of energy within a material. Materials "talk" when they are in trouble. AE equipment can be used to listen to the sounds or "noise" of material interactions during machining process, crack propagation, fibres breakage and other modes of active damage in stressed material.

Several other researchers like Liang and Dornfeld (1989), Granata et al, (1990), Karmarthi et al, (2000), Kannatey-Asibu and Dornfeld, (1981), Bukkapatnam et al (1999), have contributed to the scientific knowledge in the field of manufacturing using AE technique like: (1) Tool Wear Detection Using Time Series Analysis of Acoustic Emission, (2) Acoustic Emission Potential in Intelligent Manufacturing, (3) Flank Wear Estimation in Turning through Wavelet Representation of Acoustic Emission Signals, (4) Analysis of Acoustic Emission Signals in Machining. Judging from the above research review, it can be said that: (1) AE signals can be characterised and represented provided the acoustic sensor can detect the measurand, (2) Tool failure could be detected using AE signals and either, wavelet analysis, neural network, theoretical relations, or time series analysis, (3) Further research work needs to be done to study the effects of cutting conditions on AE signal parameters and as a result generate a model to monitor machining operation.

The objective of this work is to investigate the correlation between the acoustic emission signals and the cutting parameters in order to: (1) determine the effects of feed, speed and tool condition on acoustic emission signals in response to the deformation in the cutting zone during turning operations (2) generate a quantitative model relating acoustic emission signals with the cutting parameters.

\section{EXPERIMENTAL METHOD}

The experimental set up, as shown in schematic diagram (Fig. 1) and pictorial view (Plate 1), works on the following principle. The Clausing Engine Lathe's Spindle (1) rotates the work piece (Specimen) (3) clamped by the chuck (2) at a specified feed and cutting speed. The lathe sad- 
dle that houses the single point tool (4) via the tool holder (10) engages the rotating work piece for turning operation. The sensor (5) senses AE Signals from the turning operation, and then, the amplified signal through the preamplifier (7) is further transmitted to the data acquisition instrument (9) for processing and analysis. The sensor's cable (6) and the preamplifier cable (8) transmit the data.
The experiment is designed using factorial design method. Factorial design is applied in investigating the effect of cutting conditions on acoustic emission parameters for two quantitative and one qualitative variables namely: Speed, S, (rev/min), Feed, F, (in/rev), and Tool Condition respectively.

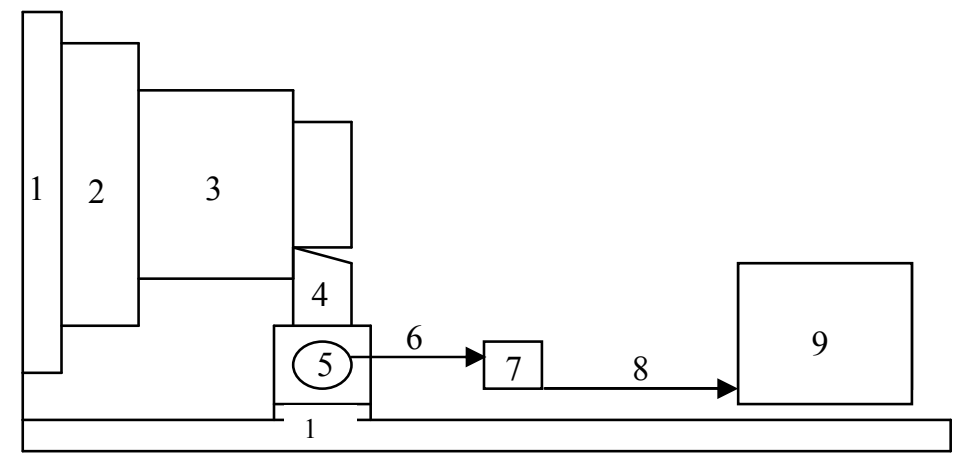

Fig. 1: Schematic Diagram of Experimental Set Up

The design matrix is as shown in Fig. 3, which shows the variables in ranges of two points such that the points take on high (+) and low (-) values for each variable. The possible number of associations for the three variables in two ranges is $2^{3}$. The eight points on the corners of the cube depict this.

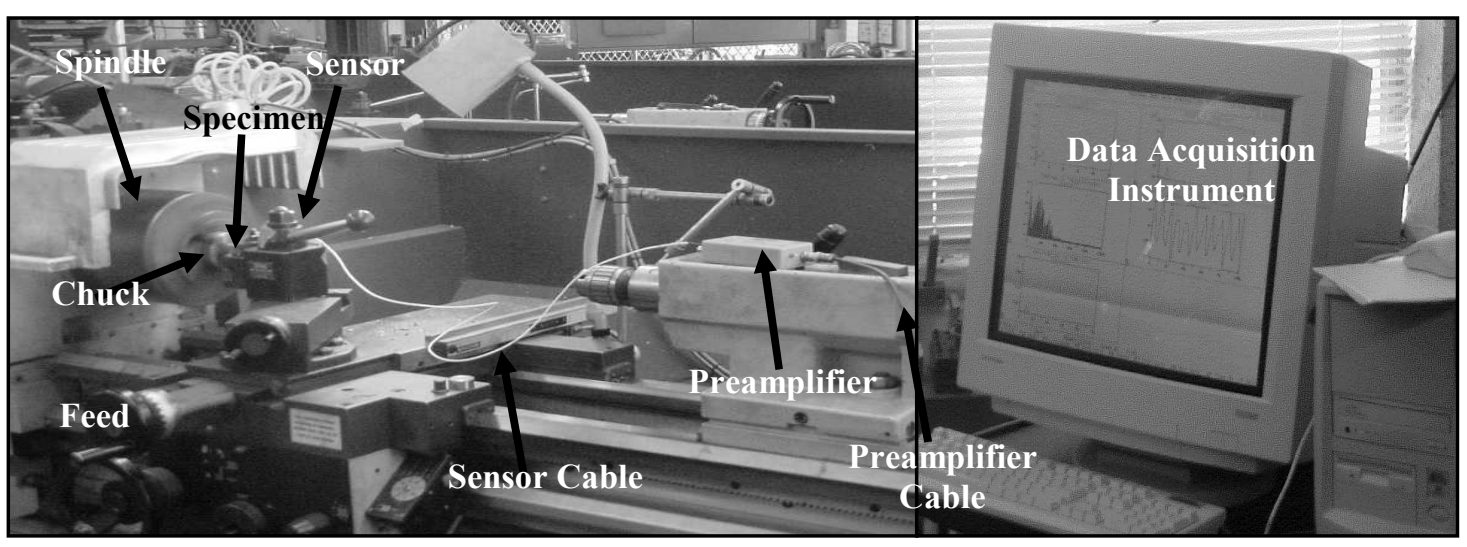

Plate 1: Pictorial View of Experimental Set Up 


\section{SELECTION OF CUTTING \& SIGNAL PARAMETERS}

Plain carbon steel (AISI 1018) 1.25 inches $(30.63 \mathrm{~mm})$ diameter cylindrical blanks were used as the material to be machined, due to its wide applications in the design of machine parts. High-speed steel cutting tool bit material was chosen for the single point tool due to its cost effectiveness in the machining of plain carbon steels. From machinery's handbook, the machining of an AISI 1018 steel material requires a cutting speed range of 70-120 ft/min (21.34$36.58 \mathrm{~m} / \mathrm{min}$ ) during turning operation using high speed steel single point tool, based on feed of $0.012 \mathrm{in} / \mathrm{rev}(0.3048 \mathrm{~mm} / \mathrm{rev})$ and depth of cut of $0.0125 \mathrm{in}$. (0.3175mm) (Oberg, et. al, 1986).

Based on the above information, the spindle speed was calculated from the cutting speed range using the formula:

$$
N=V / \pi D
$$

$\mathrm{rev} / \mathrm{min}$ where $\mathrm{D}$ is the work piece diameter. The resulting spindle speed range was 214-367 rev/ min. Based on this speed range, spindle speeds of $250,300,350$ and $400 \mathrm{rev} / \mathrm{min}$ were selected for a test run using the experimental set-up, in order to know the speed that gives detectable AE signal representation and characterization. It turned out that; the speed of $300 \mathrm{rev} / \mathrm{min}$ was the most appropriate. Thus, spindle speed 300rev/ min was selected as the centre point with \pm 100 as the variation. The feed range was selected based on the surface roughness. The best and worse roughness conditions were at positions of (high speed, low feed) and (low speed, high feed). The economic surface finish resulting from turning is given as 32-250 $\mu$ in (Groover, 1999).

The theoretical roughness value is given in a relation as (Groover, 1999).

$$
R_{i}=f^{2} /(32 N R)
$$

Where;

$$
\begin{array}{lll}
\mathrm{R}_{\mathrm{i}} & = & \text { Surface roughness (in), } \\
\mathrm{f} & = & \text { Feed (in } / \mathrm{rev} \text { ) and } \\
\mathrm{NR} & = & \text { Nose radius (in). }
\end{array}
$$

For a single point tool in turning, the nose radius should not exceed 0.005 in., if a good to best finish is desired (Groover, 1999). From the roughness equation, the feed values of the extreme conditions are calculated as follows:

\section{Regularly Worn Tool:}

Choose

$\mathrm{R}_{\mathrm{i}}=250 \mu \mathrm{in}$, with $\mathrm{NR}=0.05 \mathrm{in}$.

$\left(\mathrm{R}_{\mathrm{i}}=0.00635 \mathrm{~mm}\right.$, with $\left.\mathrm{NR}=1.27 \mathrm{~mm}\right)$

$\mathrm{f}=\left(250 \times 10^{6} \times 32 \times 0.05\right)^{1 / 2}=0.02 \mathrm{in} / \mathrm{rev}$ $(0.508 \mathrm{~mm} / \mathrm{rev})$

\section{Sharp Tool:}

Choose

$\mathrm{R}_{\mathrm{i}}=60 \mu \mathrm{in}$, with $\mathrm{NR}=0.005 \mathrm{in}$.

$\left(\mathrm{R}_{\mathrm{i}}=0.09144 \mathrm{~mm}\right.$, with $\left.\mathrm{NR}=0.127 \mathrm{~mm}\right)$

$\mathrm{f}=\left(60 \times 10^{6} \times 32 \times 0.005\right)^{1 / 2}=3.098 \times$

$$
10^{-3} \mathrm{in} / \mathrm{rev}(0.0787 \mathrm{~mm} / \mathrm{rev}) \text {. }
$$

Thus cutting feed of $0.0055 \mathrm{in} / \mathrm{rev}(0.1397 \mathrm{~mm} /$ $\mathrm{rev})$ and $0.02 \mathrm{in} / \mathrm{rev}(0.508 \mathrm{~mm} / \mathrm{rev})$ were selected as the lower and higher values respectively.

The tool condition was selected based on qualitative measures. The two extreme conditions assumed the use of a sharp and regularly worn cutting edge. The regularly worn tool edge has a flank wear of depth $0.3 \mathrm{~mm}$.

For most real signals, exact discrete representations of the input analog signal frequency and amplitude content are not possible or practical. Setting the sample rate, $\mathrm{f}_{\mathrm{s}}$ at five times the maximum signal frequency together with large values of total sampling time is recommended to minimize spectral leakage and provide a good approximation of the original signal. Generally, noise level in AE testing has proved suitable for perhaps $90 \%$ in the range of 50 to $100 \mathrm{kHz}$ (Davis, 1989). Based on this the hardware parameters were set up as follows; 
i) Sampling Frequency $4000 \mathrm{kHz}$

ii) Threshold Frequency $35 \mathrm{~dB}$

iii) Band Pass Filter $\quad 100-400 \mathrm{kHz}$

iv) Preamplifier Gain $\quad 40 \mathrm{~dB}$

The sampling frequency's selection was checked using trial and error method. Starting with sampling frequency of $2 \mathrm{MHz}$, the sampling frequency was increased at a constant rate of $500 \mathrm{kHz}$ to $3.5 \mathrm{MHz}$ where a change in the sample frequency does not change the output waveform. Thus the sampling frequency was fixed at
$4 \mathrm{MHz}$, and the resulting waveform had following measurement: Number of Sampling Points $(\mathrm{N})$ as 1024; Sampling Period (delta T) as $0.25 \mu \mathrm{s}$; and Total Period (T) per hit as $260 \mu$ s. The sampling frequency is about five times the highest frequency range of the wide bandwidth sensor and $\mathrm{N}$ is relatively large. This is consistent with the requirement for good sampling to avoid aliasing.

Arranging the cutting conditions in a factorial design matrix, and a corresponding table form, results in Fig. 2 and Table 1.

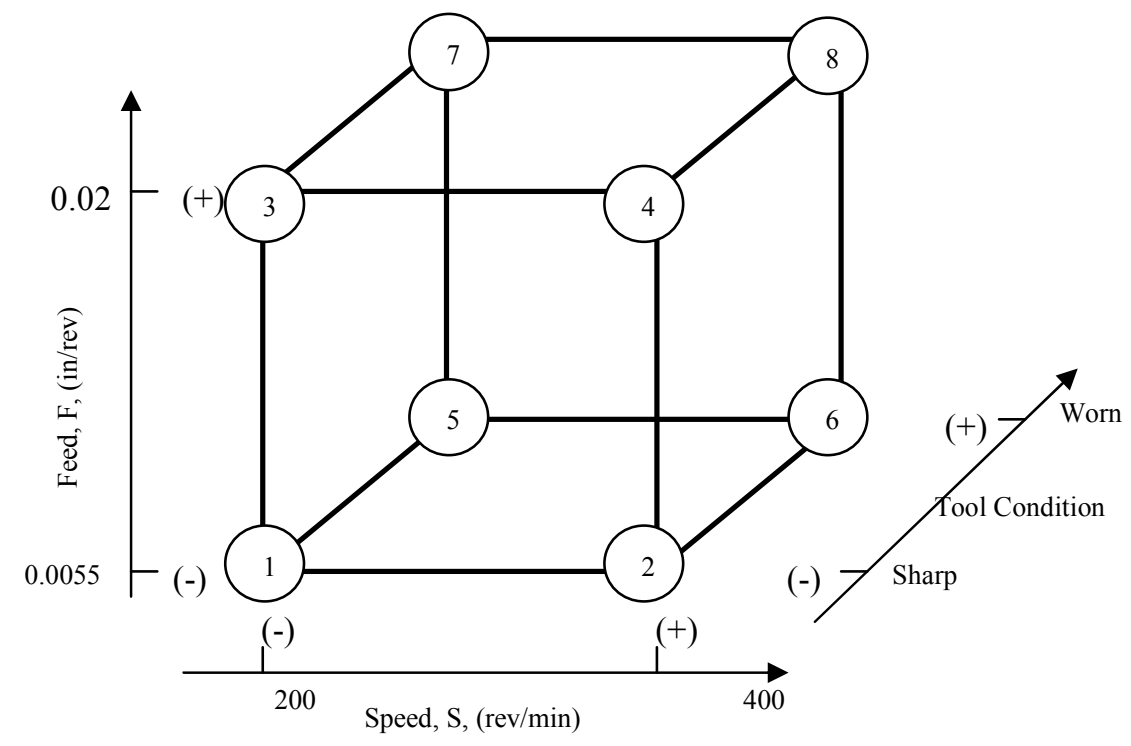

Fig.. 2: Factorial Design Matrix with Cutting Parameters

Table.1: Cutting Conditions in Tabular Form

\begin{tabular}{cccccc}
\hline Run Order & $\begin{array}{c}\text { Factorial } \\
\text { Points }\end{array}$ & Tool condition & $\begin{array}{c}\text { Depth of cut } \\
\text { (inches) }\end{array}$ & $\begin{array}{c}\text { Spindle Speed } \\
\text { (rpm) }\end{array}$ & $\begin{array}{c}\text { Feed } \\
\text { (in/rev) }\end{array}$ \\
\hline 8 & 1 & Sharp & 0.125 & 200 & 0.0055 \\
5 & 2 & Sharp & 0.125 & 400 & 0.0055 \\
2 & 3 & Sharp & 0.125 & 200 & 0.02 \\
4 & 4 & Sharp & 0.125 & 400 & 0.02 \\
7 & 5 & Worn & 0.125 & 200 & 0.0055 \\
6 & 6 & Worn & 0.125 & 400 & 0.0055 \\
1 & 7 & Worn & 0.125 & 200 & 0.02 \\
3 & 8 & Worn & 0.125 & 400 & 0.02 \\
\hline
\end{tabular}

Journal of Science and Technology, Vol. 27, No. 3, December 2007 
PROCEDURE IN DATA COLLECTION

i) Randomly select a factorial point for the experimental run.

ii) Cut specimen and identify factorial point on each specimen as indicated by the factorial design matrix.

iii) Position work piece and cutting tool in the lathe machine.

iv) $\mathrm{AE}$ sensor connected to IBM computer through a preamplifier using sensor cable is positioned on the surface of tool post with a securing tape. Care must be taken in ensuring that a couplant is applied in between the sensor and the surface of the tool post in order to avoid any vacuum, since AE signals do not transmit through a vacuum.

v) Set cutting conditions on the lathe machine to correspond to the specimens factorial point parameters and start machining.

vi) Start the AE System's computer for signal acquisition by hitting 'enter' of the system's computer keyboard.

vii) Repeat steps iii, iv, and v, according to the random run order (in order to eliminate bias in the experiment) and the cutting conditions indicated in Table 1.

viii) Repeat experiment for every factorial point in the design matrix.
Three AE signal responses namely Energy, Amplitude, and Frequency of counts waveform were selected from the data where average value, standard deviation, and percentage tolerance were calculated for the middle fifteen hits at $95 \%$ confidence interval. The results are as shown in Table 2 .

\section{DISCUSSION}

Two quantitative variables namely Feed (F, in/rev or $\mathrm{mm} / \mathrm{rev}$ ), Spindle Speed (S, rev/min) and one qualitative variable Tool Condition, T, were used to investigate the effects of cutting conditions on the acoustic emission response. Table 3 shows the recorded data with the levels coded, such that the minus sign represents the low level and a plus sign the high level for the Energy Response. It does not matter here which is associated with the plus as long as the labelling is consistent. A display of levels to be run in a design such as is given in Table 3 is called a 'design matrix' (Box, 1978).

\section{Calculation of Effects}

To determine the main effect of each of the variable on the response, that is the change in the response as we move from the low to the high version of that factor, here, from the low to the high level of feed, and cutting speed and sharp to

Table 2: Summary of Average Response for the selected Hits

\begin{tabular}{ccccccccccc}
\hline \multirow{2}{*}{$\begin{array}{c}\text { Run } \\
\text { Order }\end{array}$} & PTS & \multicolumn{3}{c}{ Energy $\left(\mathbf{v}^{2} \mathbf{s}\right)$} & \multicolumn{3}{c}{ Response } \\
Amplitude (v) & \multicolumn{3}{c}{ Frequency (kHz) } \\
& & T1 & T2 & AVG. & T1 & T2 & AVG. & T1 & T2 & AVG. \\
\hline PT7 & 1 & 1777 & 2753 & 2265 & 68 & 70 & 69 & 106 & 106 & 106 \\
PT6 & 2 & 5058 & 6504 & 5781 & 74 & 71 & 72.5 & 151 & 159 & 155 \\
PT1 & 3 & 1775 & 2079 & 1927 & 69 & 71 & 70 & 86 & 93 & 89.5 \\
PT3 & 4 & 2789 & 4603 & 3696 & 77 & 77 & 77 & 135 & 141 & 138 \\
PT8 & 5 & 2479 & 2462 & 2471 & 63 & 72 & 67 & 103 & 109 & 106 \\
PT5 & 6 & 6853 & 6323 & 6588 & 70 & 72 & 71 & 143 & 151 & 147 \\
PT2 & 7 & 1979 & 2293 & 2136 & 72 & 63 & 67.5 & 77 & 86 & 81.5 \\
PT4 & 8 & 4834 & 4574 & 4704 & 73 & 76 & 74 & 144 & 135 & 139.5 \\
\hline
\end{tabular}

112 Journal of Science and Technology, Vol. 27, No. 3, December 2007 
Table 3: Coded Level with Average Energy Response

\begin{tabular}{ccccc}
\hline & & Coded & & $\begin{array}{c}\text { Average Energy } \\
\text { (Q) }\end{array}$ \\
\hline 1 & - & - & - & 2265.25 \\
2 & + & - & - & 5781.15 \\
3 & - & + & - & 1926.65 \\
4 & + & + & - & 3696.05 \\
5 & - & - & + & 2470.7 \\
6 & + & - & + & 6588.15 \\
7 & - & + & + & 2136.15 \\
8 & + & + & + & 4704.2 \\
\hline
\end{tabular}

dull tool. Consider the first two results in Table 3. Besides experimental error, the corresponding response (2265.25 and 5781.15) differs only because of the speed. The feed, F, and the tool condition, T, are the same for both of these conditions. Since there are four measures of the speed effect at each of the four combinations of conditions of the other variables as listed, condition at each comparison is made. The average of these four measures is called the main effect of that factor (variable) which can be found by the following formulas:

The main effect of cutting speed $\left(E_{S}\right)$ is given as:

$E_{s}=1 / 4\left(\left(Q_{2}+Q_{4}+Q_{6}+Q_{8}\right)-\left(Q_{1}+Q_{3}+Q_{5}+Q_{7}\right)\right)$

Where $Q_{i}$ refers to the Energy response at the $i^{\text {th }}$ point.

The main effect of the feed $\left(\mathrm{E}_{\mathrm{F}}\right)$ is given as:

$E_{f}=1 / 4\left(\left(Q_{3}+Q_{4}+Q_{7}+Q_{8}\right)-\left(Q_{1}+Q_{2}+Q_{5}+Q_{6}\right)\right)$

The main effect of tool condition $\left(\mathrm{E}_{\mathrm{T}}\right)$ is given as:

$E_{T}=1 / 4\left(\left(Q_{5}+Q_{6}+Q_{7}+Q_{8}\right)-\left(Q_{1}+Q_{2}+Q_{3}+Q_{4}\right)\right)$

The two-factor effect is a measure of the interactions of any two variables. It is found by the difference between the average of low combined variable effects and high combined variable effects. By convention, half the difference is called the first variable by second variable interaction. The interaction may equally well be thought of as one-half the difference in the average second variable effects at the two levels of first variable. Like the main effects, the interaction effect is seen to be a difference between two averages; half of the eight results being included in one average and half in the other. Just as main effects may be viewed as a contrast between observations on parallel faces of the cube, as shown in Fig. 3, the interaction is a contrast between results on two diagonal planes (Box, et. al., 1978).

The S x F, S x T, and F x T interactions are obtained by the following equations:

$$
\begin{aligned}
& I_{S F}=S \times F=1 / 4\left(\left(Q_{1}+Q_{4}+Q_{5}+Q_{8}\right)-\left(Q_{2}+Q_{3}+Q_{6}+Q_{7}\right)\right) \\
& I_{S T}=S \times T=1 / 4\left(\left(Q_{1}+Q_{3}+Q_{6}+Q_{8}\right)-\left(Q_{2}+Q_{4}+Q_{5}+Q_{7}\right)\right) \\
& I_{F T}=F \times T=1 / 4\left(\left(Q_{1}+Q_{2}+Q_{4}+Q_{8}\right)-\left(Q_{3}+Q_{4}+Q_{5}+Q_{6}\right)\right)
\end{aligned}
$$

The three-factor interaction effect is defined as the one-half the difference of first two variables interactions with the two levels of the third variable. Thus:

$I_{S F T}=S \times F \times T=1 / 4\left(\left(Q_{2}+Q_{3}+Q_{5}+Q_{8}\right)-\left(Q_{1}+Q_{4}+Q_{6}+Q_{7}\right)\right)$

The mean of the runs is defined as E:

$E_{M}=1 / 8\left(Q_{1}+Q_{2}+Q_{3}+Q_{4}+Q_{5}+Q_{6}+Q_{7}+Q_{8}\right)$

The table of signs in Table 3 can characterize the calculations performed to obtain the various effects and the results obtained for each of the effect are shown in Table 4. Applying equations 2, $3,4,5,6,7$ and 8 using the values of Q from Table 4 results:

$\mathrm{E}_{\mathrm{S}}=2993$,

$\mathrm{E}_{\mathrm{F}}=-1161$,

$\mathrm{E}_{\mathrm{T}}=558$,

$\mathrm{I}_{\mathrm{SF}}=-823.97$,

$\mathrm{I}_{\mathrm{ST}}=350.05$,

$\mathrm{I}_{\mathrm{FT}}=51.30$,

$\mathrm{I}_{\mathrm{SFT}}=49.275$. 
Table 4: Effects for Energy Response

\begin{tabular}{|c|c|c|c|c|c|c|c|c|}
\hline \multirow{2}{*}{ PTS } & \multicolumn{3}{|c|}{ Coded } & \multicolumn{4}{|c|}{ Combinations } & \multirow{2}{*}{$\begin{array}{c}\text { Average Energy } \\
\left(Q \text { in } v^{2} s\right)\end{array}$} \\
\hline & $\mathbf{S}$ & $\mathbf{F}$ & $\mathbf{T}$ & SF & ST & FT & SFT & \\
\hline 1 & - & - & - & + & + & + & - & 2265.25 \\
\hline 2 & + & - & - & - & - & + & + & 5781.15 \\
\hline 3 & - & + & - & - & + & - & + & 1926.65 \\
\hline 4 & + & + & - & + & - & - & - & 3696.05 \\
\hline 5 & - & - & + & + & - & - & + & 2470.7 \\
\hline 6 & + & - & + & - & + & - & - & 6588.15 \\
\hline 7 & - & + & + & - & - & + & - & 2136.15 \\
\hline 8 & + & + & + & + & + & + & + & 4704.2 \\
\hline
\end{tabular}

Calculation of Standard Errors for Effects using Replicated Runs

When genuine run replicates are made under a given set of experimental conditions, the variation between their associated observations may be used to estimate the standard deviation of a single observation and hence the standard deviation of the effects. A genuine run replicate must involve the taking of all the steps under the same conditions again. In general, if $g$ sets of experimental conditions are genuinely replicated and the $n_{\mathrm{i}}$ replicate runs made at the ith set yield an estimate $s_{i}^{2}$ of $\mathrm{s}_{\mathrm{i}}^{2}$ having $v_{i}=n_{\mathrm{i}}-1$ degrees of freedom, then, the pooled estimated of run variance is given as (Box, et. al., 1978):

$s^{2}=\frac{v_{1} s_{1}^{2}+v_{2} s_{2}^{2}+v_{3} s_{3}^{2}+\ldots+v_{g} s_{g}^{2}}{v_{1}+v_{2}+v_{3}+\ldots+v_{g}}$

with $v=v_{1}+v_{2}+v_{3}+\quad+v_{g}$ degrees of freedom. With only $n_{i}=2$ replicates at each of the gets of conditions, the formula for the ith variance reduces to

$s_{i}^{2}=d_{i}^{2} / 2 \quad \begin{aligned} & \text { with } v_{i}=1, \text { where } d_{i} \text { is the differ- } \\ & \text { ence between the duplicate observa- }\end{aligned}$ tions for the ith set of conditions. Thus Eq. 10 yields:

$$
s^{2}=\Sigma^{d_{i}^{2}} / 2 g
$$

Since each main effect and interaction is a statistic of the form

$$
Y_{m+}-Y_{m-}
$$

where each average contains eight observations, the variance of each effect $\left(V_{\text {effect }}\right)$ (assuming independent errors) is given by:

$$
V_{\text {effect }}=V\left(Y_{m+}-Y_{m-}\right)=\left(\frac{1}{8}+\frac{1}{8}\right) \sigma^{2}=\frac{1}{4} \sigma^{2}
$$

In general, if a total of $\mathrm{N}$ runs is made in conducting a two-level factorial or replicated factorial design, then $\mathrm{V}_{\text {effect }}$ is given as:

$$
V(\text { effect })=\frac{4}{N} \sigma^{2}
$$

$S \tan$ dard_Error $_{-}\left(S_{e}\right)=1.96 \sqrt{V(\text { Effect })}$

The result obtained for the standard error is as shown in Tables 5 and 6 .

From equations 11 and 12, and using Table 5, the standard error is computed as 328. An effect or interaction is considered significant if its range $\left(E_{s} \pm S_{e}\right)$ does not include zero. Higher interactions indicate that different conclusions may be reached for different settings of one of the variables.

From Table 6, the energy response suggest that, as the cutting speed increases from a low value of $200 \mathrm{rev} / \mathrm{min}$, to a high value of $400 \mathrm{rev} / \mathrm{min}$, the acoustic energy increases by $2993 \pm 328$ units. As

114 Journal of Science and Technology, Vol. 27, No. 3, December 2007 
Table 5: Standard Error for Energy Response

\begin{tabular}{cccccccrr}
\hline & \multicolumn{3}{c}{ Coded } & \multicolumn{6}{c}{ Energy Response } \\
PTS & S & F & T & T1 & T2 & AVG. & \multicolumn{1}{c}{$\mathbf{d}_{\mathbf{1}}$} & S $_{\mathbf{1}}{ }^{\mathbf{2}}$ \\
\hline 1 & - & - & - & 2479 & 2462 & 2471 & 17 & 141 \\
2 & + & - & - & 6853 & 6323 & 6588 & 530 & 140185 \\
3 & - & + & - & 1979 & 2293 & 2136 & -314 & 49141 \\
4 & + & + & - & 4834 & 4574 & 4704 & 260 & 33748 \\
5 & - & - & + & 1777 & 2753 & 2265 & -976 & 476581 \\
6 & + & - & + & 5058 & 6505 & 5781 & -1447 & 1047339 \\
7 & - & + & + & 1775 & 2079 & 1927 & -304 & 46238 \\
8 & + & + & + & 2789 & 4603 & 3696 & -1813 & 1644028 \\
& & & & \multicolumn{7}{c}{ Total } \\
\hline
\end{tabular}

Table 6: Calculated Effects and Standard Error for Energy Response

\begin{tabular}{cc}
\hline \multicolumn{1}{c}{ Effect } & $\begin{array}{c}\text { Estimate } \pm \text { Standard } \\
\text { Error }\end{array}$ \\
\hline Main Effects & \\
Speed $\left(\mathrm{E}_{\mathrm{S}}\right)$ & $2993 \pm 328$ \\
Feed $\left(\mathrm{E}_{\mathrm{F}}\right)$ & $-1161 \pm 328$ \\
Condition $\left(\mathrm{E}_{\mathrm{T}}\right)$ & $558 \pm 328$
\end{tabular}

Two Factor Interactions

$\begin{array}{rl}\mathrm{I}_{\mathrm{SF}} & -823.97 \\ \mathrm{I}_{\mathrm{ST}} & \pm 328 \\ \mathrm{I}_{\mathrm{FT}} & 350 \pm 328 \\ 51 & \pm 328\end{array}$

Three Factor Interactions
$\mathrm{I}_{\mathrm{SFT}}$
$49 \pm 328$

the feed increases from low value of $0.0055 \mathrm{in} /$ rev $(0.1397 \mathrm{~mm} / \mathrm{rev})$ to a high value of $0.02 \mathrm{in} / \mathrm{rev}$ $(0.508 \mathrm{~mm} / \mathrm{rev})$, the acoustic energy decreases by $1161 \pm 328$ units. As the tool becomes dull, the acoustic energy increases. However, there is a large interaction between cutting speed and feed and cutting speed and tool condition. Thus, the above conclusions may not be appropriate and require further analysis as follows. The effects of speed, feed and tool condition cannot be interpreted separately because of the SF and ST interactions, and can at best be considered using the energy response design matrix and the two-way diagram shown in Fig. 3, Fig. 4, and Fig. 5. From figure 4, the interactions between SF evidently arise from the change in feed as speed increases. With a low feed, the effect of increasing speed results in increasing acoustic energy by 3817 units $(161 \%)$ while the effect of increasing speed at high feed, increases acoustic energy by 2168 units (107\%). At low speed, the effect of increasing the feed is a reduction of energy by 336 units (14\%) (almost insignificant considering the standard error) but at high speed the effect is a reduction of 1985 units $(32 \%)$. 


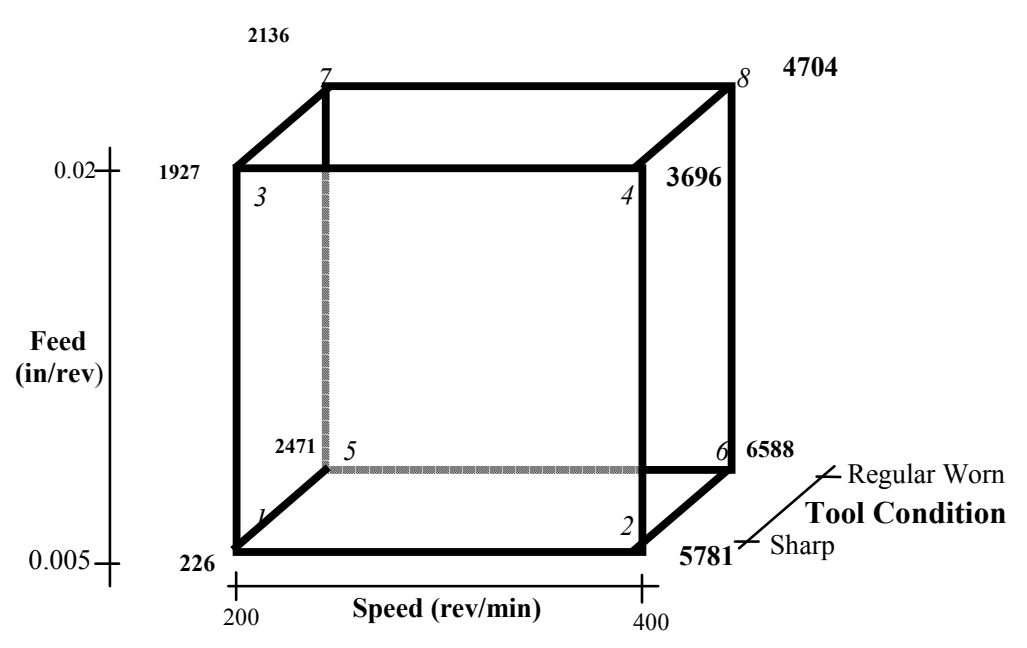

Fig. 3: Energy Response Design Matrix

From Fig. 5, the interaction of ST evidently arises from the change in tool condition as speed increases. At low speed, the tool condition has no effect on the acoustic energy. However, there is a modest increase of 907 units (19\%) at high speed as the tool wears down.

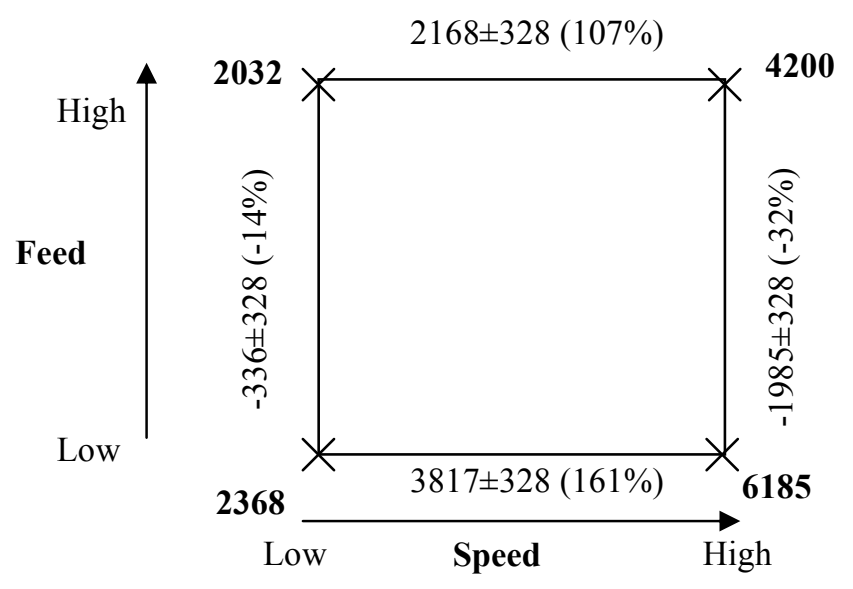

Fig. 4 : Two Way Diagram to Analyze SxF Interactions 


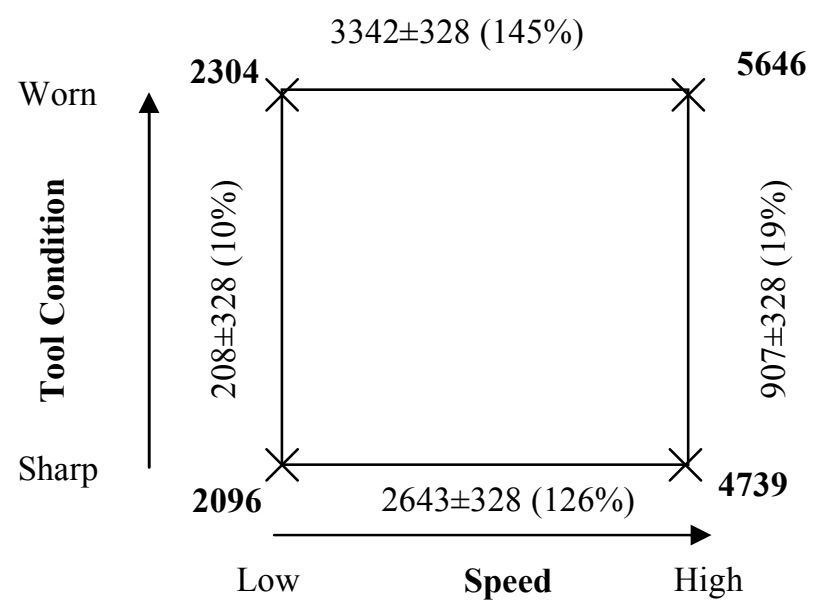

Fig. 5 : Two Way Diagram to Analyze SxT Interactions

Further analysis on the energy response using the two way diagrams of the cutting speed and feed interactions, and cutting speed and tool condition interactions have shown that; (1) increasing the feed reduces the noise energy at any given time, (2) increasing the cutting speed significantly increases the noise energy at any feed or tool condition, (3) the tool condition is the least variable affecting the acoustic energy level. This seemingly is contrary to expectation, how-

Table 7: Calculated Effects and Standard Error for Frequency Response

\begin{tabular}{cc}
\hline \multicolumn{1}{c}{ Effect } & $\begin{array}{c}\text { Estimate } \pm \text { Stan- } \\
\text { dard Error }\end{array}$ \\
\hline Main Effects & \\
Speed $\left(\mathrm{E}_{\mathrm{S}}\right)$ & $68.69 \pm 12.5$ \\
Feed $\left(\mathrm{E}_{\mathrm{F}}\right)$ & $-43.79 \pm 12.5$ \\
Condition $\left(\mathrm{E}_{\mathrm{T}}\right)$ & $1.59 \pm 12.5$ \\
Two Factor Interactions & \\
$\mathrm{I}_{\mathrm{SF}}$ & $-24.44 \pm 12.5$ \\
$\mathrm{I}_{\mathrm{ST}}$ & $-22.27 \pm 12.5$ \\
$\mathrm{I}_{\mathrm{FT}}$ & $26.18 \pm 12.5$ \\
Three Factor Interactions & \\
$\mathrm{I}_{\mathrm{SFT}}$ & $26.36 \pm 12.5$ \\
\hline
\end{tabular}

ever the explanation is that the cutting tool used as dull (worn) in this experiment has flank wear depth of $0.3 \mathrm{~mm}$, which is approximately sharp.

Similarly, the analysis for the frequency and amplitude response using data from table 2 are as shown in Tables 7 and 8 respectively.

From Table 7, the frequency response suggests that, as the cutting speed increases, the acoustic frequency increases by $68.69 \pm 12.5$ units, whiles the acoustic frequency decreases as the feed increases. The tool condition has no significant effect on the acoustic frequency. However, there is a significant interaction between the cutting speed, feed, and tool condition, thus making the main effects inconclusive. Further analysis using time series approach is recommended.

From Table 8, the amplitude response suggest that, as the speed increases from a low value of $200 \mathrm{rev} / \mathrm{min}$, to a high value of $400 \mathrm{rev} / \mathrm{min}$, the acoustic amplitude increases by 4.11 units. As the feed increases from low value of $0.0055 \mathrm{in} / \mathrm{rev}$ $(0.1397 \mathrm{~mm} / \mathrm{rev})$ to a high value of $0.02 \mathrm{in} / \mathrm{rev}$ $(0.508 \mathrm{~mm} / \mathrm{rev})$, the acoustic amplitude increases by 3.04 units. There is insignificant change in the acoustic amplitude as the tool becomes dull. 
Table 8: Calculated Effects and Standard Error for Amplitude Response

\begin{tabular}{lc}
\hline \multicolumn{1}{c}{ Effect } & $\begin{array}{c}\text { Estimate } \pm \\
\text { Standard Error }\end{array}$ \\
\hline Main Effects & \\
Speed $\left(\mathrm{E}_{\mathrm{S}}\right)$ & $4.11 \pm 1.3$ \\
Feed $\left(\mathrm{E}_{\mathrm{F}}\right)$ & $3.04 \pm 1.3$ \\
Condition $\left(\mathrm{E}_{\mathrm{T}}\right)$ & $1.68 \pm 1.3$ \\
Two Factor Interactions & \\
$\mathrm{I}_{\mathrm{SF}}$ & $-1.01 \pm 1.3$ \\
$\mathrm{I}_{\mathrm{ST}}$ & $-0.78 \pm 1.3$ \\
$\mathrm{I}_{\mathrm{FT}}$ & $0.19 \pm 1.3$ \\
Three Factor Interactions & \\
$\mathrm{I}_{\mathrm{SFT}}$ & $-0.74 \pm 1.3$ \\
\hline
\end{tabular}

Also, the interaction between the speed, feed, and tool condition is insignificant, thereby making the main effects 'real'.

\section{GENERATION OF MODEL}

The discussion of results revealed significant interactions between cutting speed, feed, and tool condition for the acoustic energy response. The acoustic amplitude and frequency response shows insignificant and more significant interaction among the cutting conditions respectively. As discussed, the main effects of cutting speed, feed, and tool condition for the acoustic amplitude response can be interpreted individually whiles the acoustic frequency response results require further analysis. Since the frequency response requires further analysis, a model is generated from the acoustic energy response and acoustic amplitude response. From table 6, a model governing the acoustic energy response and the cutting conditions is given as:

Energy Response (Q)

$$
\begin{aligned}
\mathrm{Q}= & \mathrm{Q}_{\mathrm{M}}+2993 \mathrm{~S}-1161 \mathrm{~F}+558 \mathrm{~T}-824 \mathrm{SF} \\
& +350 \mathrm{ST}
\end{aligned}
$$

Where;

$\mathrm{Q}=$ Acoustic Energy Response $(\mathrm{db})$

$\mathrm{Q}_{\mathrm{M}}=$ Average Energy $(\mathrm{db})$

$\mathrm{S}=$ Cutting Speed
$\mathrm{F}=$ Feed.

$\mathrm{T}=$ Tool condition.

Note that values of S, F, and T are \pm 1

Also, from table 8, a model governing the amplitude response and the cutting conditions is given as:

Amplitude Response (A)

$\mathrm{A}=\mathrm{A}_{\mathrm{M}}+4.11 \mathrm{~S}+3.04 \mathrm{~F}+1.68 \mathrm{~T}$

Where;

$\mathrm{A}=$ Acoustic Amplitude Response (db)

$\mathrm{A}_{\mathrm{M}}=$ Average Amplitude (db)

$\mathrm{S}=$ Cutting Speed

$\mathrm{F}=$ Feed.

$\mathrm{T}=$ Tool condition.

Note that values of $\mathrm{S}, \mathrm{F}$, and $\mathrm{T}$ are \pm 1 .

Verifying the models by re-generating model responses using coded levels for standard factorial design matrix (Table 9) and comparing results with the experimental values suggests that there is no significant difference. Further verification using ANOVA Statistical Analyzer revealed that there is no significance difference. $M$ and $E$ represents Model and Experimental respectively in table 9.

For a machining operation, the cutting speed and the feed are input cutting parameters to the machine tool, whiles the cutting tool (tool condition) is positioned. Once machining commences and progresses, the cutting speed and the feed become fixed whiles the cutting tool condition changes from sharp to dull. Therefore, for constant cutting speed and feed, the acoustic energy model reduces to:

$$
\mathrm{Q}=\mathrm{a}_{0}+\mathrm{a}_{1} \mathrm{~T}
$$

Where;

$$
\begin{aligned}
& \mathrm{a}_{0}=\mathrm{Q}_{\mathrm{M}}+2993 \mathrm{~S}-1161 \mathrm{~F}-824 \mathrm{SF} \\
& \mathrm{a}_{1}=350 \mathrm{~S}+558
\end{aligned}
$$

\section{MONITORING SYSTEM}

A quasi-automatic monitoring system is presented, based on the experimental data collected

118 Journal of Science and Technology, Vol. 27, No. 3, December 2007 
Table 9: Verification of Energy and Amplitude Response Model

\begin{tabular}{ccccccccc}
\hline $\mathrm{S}$ & $\mathrm{F}$ & $\mathrm{T}$ & $\mathrm{SF}$ & $\mathrm{ST}$ & $\mathrm{M}_{\mathrm{Q}}$ & $\mathrm{E}_{\mathrm{Q}}$ & $\mathrm{M}_{\mathrm{A}}$ & $\mathrm{E}_{\mathrm{A}}$ \\
\hline-1 & -1 & -1 & 1 & 1 & 2472 & 2471 & 67.005 & 67.44 \\
1 & -1 & -1 & -1 & -1 & 6639 & 6588 & 71.115 & 70.5 \\
-1 & 1 & -1 & -1 & 1 & 2135 & 2156 & 70.045 & 70.4 \\
1 & 1 & -1 & 1 & -1 & 4654 & 4704 & 74.155 & 74 \\
-1 & -1 & 1 & 1 & -1 & 2264 & 2265 & 68.685 & 69.27 \\
1 & -1 & 1 & -1 & 1 & 5731 & 5781 & 72.795 & 72.4 \\
-1 & 1 & 1 & -1 & -1 & 1927 & 1927 & 71.725 & 70.37 \\
1 & 1 & 1 & 1 & 1 & 3746 & 3696 & 75.835 & 77 \\
\hline
\end{tabular}

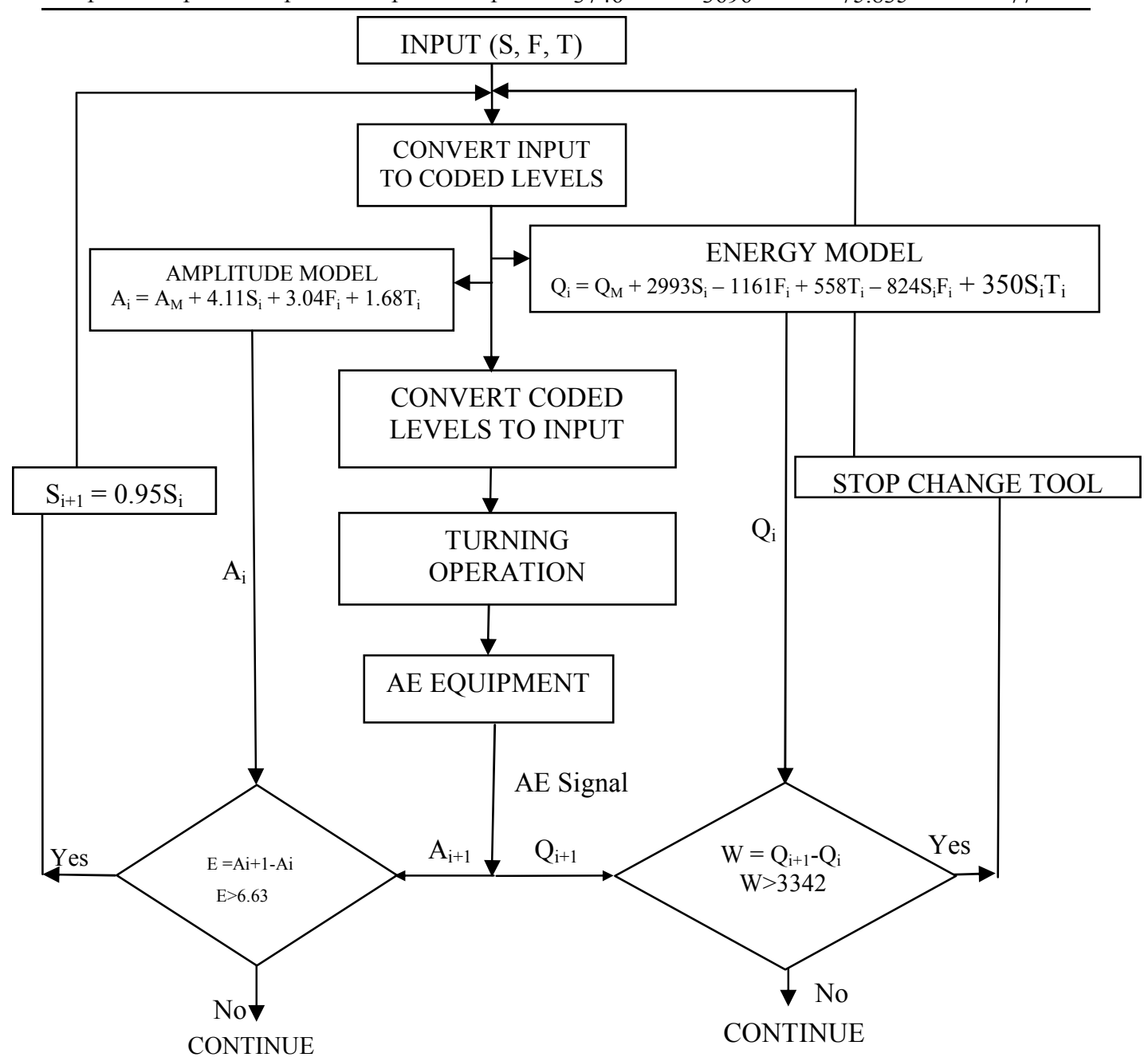

Figure 6: Tool Condition Monitoring Algorithm (Flow Chart) 
and the generated model. The monitoring flow chart shown in Fig. 6 is intended for an operator to change the cutting tool. From the flow chart, a change in the tool condition will cause an increase in the acoustic energy response. Comparisons of the two successive acoustic energy responses, and or acoustic amplitude responses suggest the condition of the cutting tool and the corresponding cutting speed control during turning operation. A change in cutting tool will be indicated when a critical condition is met. A change in the cutting speed is presented for completeness.

\section{CONCLUSION}

The primary goal of this work was to investigate the correlation between the acoustic emission signals and the cutting parameters in order to determine the effects of feed, speed and tool condition on acoustic emission signals in response to the deformation in the cutting zone during turning operations and also to generate a quantitative model relating acoustic emission signals with the cutting parameters. By observation of the acoustic emission signal's waveform, it can be said that there is a correlation between the acoustic emission signals and the cutting zone deformation of AISI 1018 steel material during turning operation. The following conclusions are drawn based on the range of cutting conditions considered:

- The acoustic energy response revealed a significant interaction between the cutting speed and feed, and a little interaction between speed and tool condition.

- The generated acoustic energy model reveals that the acoustic noise energy increases as the cutting tool becomes dull, for a given cutting speed and feed.

- The amplitude model reveals a dominant effect of cutting speed over feed and tool condition making it useful in controlling the cutting speed as the cutting tool becomes dull.
- The monitoring system suggest that, tool condition and cutting speed may be monitored using acoustic energy response and acoustic amplitude response respectively, during machining operation and it is recommended for use instead of the human elements.

\section{REFERENCES}

Box, G.P., Hunter, W.G. and Stuart Hunter, J., (1978), Statistics for Experiments, John Wiley \& Sons, Inc. 1978, pp. 306-344

Bukkapatnam, S.T.S., (1999), Analysis of Acoustic Emission Signals in Machining, Journal of Manufacturing Science and Engineering, ASME. 121, (4): 568-576

Cho, S.S. and Komvopoulos, K., (1997). Correlation Between Acoustic Emission and Wear of Multilayer Ceramic Coated Carbide Tools. Journal of Manufacturing Science and Engineering, ASME, 119: 238-245

Davis, J. R., (1989), Metals Handbook, Ninth Edition, Non Destructive Evaluation, ASM International. 17: 279-280

Granata, D.M., (1990). Acoustic Emission Potential in Intelligent Manufacturing, Journal of Advanced Metallic and Ceramic Materials, IEEE, pp.1249-1254.

Groover, M. P., (1999). Fundamentals of modern manufacturing materials, processes and systems, John Willy \& Sons Inc. 1999, pp. 633-634

Karmarthi, S.V, (2000). Flank Wear Estimation in Turning through Wavelet Representation of Acoustic Emission Signals. , Journal of Manufacturing Science and Engineering, ASME. 122 (1): 12-19

Kannatey-Asibu, E. and Donfeld, D. A., (1981). Quantitative Relationships for Acoustic Emission from Orthogonal Metal Cutting, Journal of Engineering for Industry, ASME International, 103: 330-340 
Liang, S.Y. and Dornfeld, D.A., (1989). Tool Wear Detection Using Time Series Analysis of Acoustic Emission. Journal of Engineering for Industry, ASME, 111: 199-204

Miller, R.K. and Mclntire, P., (1987). Acoustic Emission Testing, $2^{\text {nd }}$ Ed., Non Destructive Testing Handbook, ASME International, 5: 275- 279
Oberg, E, Jones, F. D., and Horton, H. L., (1986). Machinery's hand-book $22^{\text {nd }}$ revised edition, Industrial Press Inc. 1986. pp. 1765-1771

Salameh, M, (2001). http: //home.tir.com/ ms/ personal / personal.html 